\title{
GCU
}

Glasgow Caledonian

University

University for the Common Good

\section{Ripping the pith from the Peel: Institutional and Internet cultures of archiving pop} music radio

Garner, Ken

Published in:

Radio Journal -Intellect-

DOI:

10.1386/rjao.10.2.89_1

Publication date:

2012

Document Version

Author accepted manuscript

Link to publication in ResearchOnline

Citation for published version (Harvard):

Garner, K 2012, 'Ripping the pith from the Peel: Institutional and Internet cultures of archiving pop music radio', Radio Journal -Intellect-, vol. 10, no. 2, 1, pp. 89-112. https://doi.org/10.1386/rjao.10.2.89_1

\section{General rights}

Copyright and moral rights for the publications made accessible in the public portal are retained by the authors and/or other copyright owners and it is a condition of accessing publications that users recognise and abide by the legal requirements associated with these rights.

Take down policy

If you believe that this document breaches copyright please view our takedown policy at https://edshare.gcu.ac.uk/id/eprint/5179 for details of how to contact us. 


\section{Ripping the pith from the Peel:}

\section{Institutional and Internet cultures of archiving pop music radio}

KEN GARNER

Glasgow Caledonian University 


\section{EPIGRAPH}

The lost cannot be recovered; but let us save what remains: not by vaults and locks which fence them from the public eye and use, in consigning them to the waste of time, but by such a multiplication of copies, as shall place them beyond the reach of accident

(The Papers of Thomas Jefferson, Volume 19, January 1791 to March 1791, Princeton University Press, 1974) 


\section{ABSTRACT}

Only a small number of complete recordings of the programmes broadcast on average three times a week for 37 years by the influential BBC Radio 1 DJ John Peel (1939-2004) were ever made and preserved by the BBC sound archives, until the last four years of his life. This article seeks to explain the institutional, technological and cultural context behind this absence, and compare it with the recent practice of internet-enabled fan archiving of shows, based on the restoration and digitization of listeners' shared off-air cassette recordings. An anonymous online survey indicated the taping, sharing and archival practices and principles of more than 1,000 self-defined 'regular listeners' to Peel's programmes. Expert interviews were conducted with past and present BBC Radio archivists, and senior BBC executives directing the corporation's digital archival development. It is discovered that Peel listeners share archival, technical and ethical values with contemporary BBC archival developers, which could suggest mutually-beneficial future, crowdsourcing approaches to expanding the accessibility of musicradio archives in general. 
Citation: Garner, Ken. 2012. 'Ripping the Pith from the Peel: Institutional and Internet Cultures of archiving pop music radio', Radio Journal: International Studies in Broadcast and Audio Media, Vol 10 (2), pp. 89-112

\section{KEY WORDS}

Archive

John Peel

BBC Radio 1

Internet

Digital

Listeners

Crowdsourcing 
In many ways the online Yahoo group devoted to discussion of the late BBC Radio 1 DJ John Peel is much like others of its type. Members discuss his career, his interests and achievements. They also veer off into chat about other broadcasters, programmes, bands, websites and musical genres - complete with creative injokes, cryptic crossword-clue titles to message posts, and reflective remarks on each other's fictitious online identities. Such practices have become familiar identifiers of the playful, performative, producerly world of British radio show-related discussion boards (Thomas, 2009; Hills, 2009). But in other ways the group differs markedly. Having 857 members spread across the world, an average of more than 50 new messages in any seven-day period, and the fact that it has been consistently active at this level since its establishment in January 1999, five years before Peel's sudden death in October 2004, indicates unusual continuity. What truly separates it from other such mailing lists, however, is that many threads, constituting a large minority of discussion, document the group's original archival work. Members of the group are not just producerly in their discourse, but also in their physical actions. Over the past five years the group has digitally reconstructed more than 1300 otherwise lost radio shows presented by Peel, by ripping, sharing and combining listeners' collections of fragmentary off-air 
cassette recordings. ii There are now as a consequence more Peel shows available online, wholly or in part, than exist in the official BBC archives.

This article is an attempt to explore these off-air radio tape preservation practices of this specialist, minority-interest listening community; and whether their motivations, ethics, and evolving policies have anything in common with those of official BBC archivists. It is argued that the unique features of this case study offer lessons for other listening communities and broadcast organizations in the potential for expanding accessibility to digital radio archives. It shows how listener-based, crowdsourced archiving offers a new model of public radio archival practice, one which state, educational and commercial organisations could usefully choose to engage with, in their shared, strategic interests in the recovery and preservation of lost sound broadcasts from the pre-digital era.

Some public broadcasting organisations have in the past sought the assistance of viewers and listeners to develop their archives. But this has normally taken the form of campaigns seeking to fill known gaps in their collections, as with the BBC's Treasure Hunt campaign in 2001, which sought off-air recordings of notable, 
named pre-1980 comedy and entertainment programmes (BBC, 2001; Brown, 2005). In British television studies, this role of dedicated audiences in collectively archiving missing episodes or entire programme series is well understood. Perry and Howard (2010) have emphasised the crucial role played by Kaleidoscope, the activist pressure group of popular television fan archivists, in preserving and saving otherwise 'swiped or wiped' shows. Messenger Davies (2009) has revealed the chain of serendipitous connections that enabled societies of enthusiasts to collaborate with universities, public archives and broadcasters to preserve two or three minority-interest 'lost' TV series.

There are also a small number of recent examples of national media archiving projects utilising crowdsourcing (as defined by Howe, 2006, 2009; refined by Estelles-Arolas and Gonzalez-Ladron-deGuevara, 2012) to develop their holdings. The National Library of Australia has since 2008 encouraged users of its online newspapers archive to correct the OCR-text version of articles, displayed alongside the scan of the original newspaper page, and 3.4 million lines of text were corrected in this way in the first year alone (Campbell, 2009). Radio listeners in Denmark are being invited as part of the LARM research project to assist online in providing 
Citation: Garner, Ken. 2012. 'Ripping the Pith from the Peel: Institutional and Internet Cultures of archiving pop music radio', Radio Journal: International Studies in Broadcast and Audio Media, Vol 10 (2), pp. 89-112

metadata on digitised audio files of thousands of hours of taped material deposited with the State and University Library by the Danish Broadcasting Corporation. iii

But Peel listeners' online archiving differs from these activities in key ways, offering a fundamentally different model of archival practice. The programmes being restored did not exist in any final form (unlike a TV viewer's VHS off-air video recording of a TV show, for example) prior to the online collaboration: most tapes belonging to individual listeners exist only in part, typically one or two sides of an audio cassette, and rarely constitute a complete programme. These analogue recordings are not then handed to an official body for digitization, correction and reconstruction: this work is done collectively by listeners themselves, voluntarily. It is solely down to the online nature of the listener community, and the cheap and universal availability over the past decade of sophisticated audio digitization and correction software for home computers $^{\text {iv }}$, that this collective archiving has proved possible. These characteristics of crowdsourcing also extend to the work itself: listeners do not simply collectively provide metadata about existing recordings presented to them (as in the LARM project in Denmark), but produce by themselves the archival artifact itself, 
the digital audio file, and the accompanying metadata. What is open to enquiry is the ethical status of the work and the archive they are creating. For whom is the work being done, for whose benefit? The politically radical answer here, not previously envisaged in any definition of crowdsourcing, is that the crowd has proposed and justified the activity to itself, appealing ethically to notions of public benefit in the public ownership of cultural heritage, reflecting, they argue, John Peel's own broadcast career.

\section{THE JOHN PEEL SHOW AND THE BBC ARCHIVE}

Senior figures in the BBC share that aspiration. They too believe Peel's broadcast work is a public asset. Tony Ageh, controller of development, BBC Archive, says he believes John Peel is a 'special case' in the archive, 'one of the 20 most important people whose work has defined what the BBC is all about', and hopes his archive could 'become an exemplar' of possibilities in other areas (Ageh 1 November 2011, interview). A recent sign of this commitment is the BBC's involvement with the Arts Council in the organisation and funding of an experimental digital service to make Peel's record collection available online via the John Peel Centre for Creative Arts in Stowmarket. The BBC's role will be to 'develop the technological solutions and provide ongoing support', and has 
Citation: Garner, Ken. 2012. 'Ripping the Pith from the Peel: Institutional and Internet Cultures of archiving pop

music radio', Radio Journal: International Studies in Broadcast and Audio Media, Vol 10 (2), pp. 89-112

suggested 'there will be access to the $\mathrm{BBC}$ radio archive of Peel Sessions' (BBC, 2012).

But the fact that the organisers of this project recognise that the initial funding and six-month duration will only enable them to digitise 100 vinyl albums a week, meaning some 2,500 or 10 per cent of Peel's LPs will actually be available online by the project's end (that's not including Peel's 40,000 vinyl singles and thousands of CDs), is a sign of the sheer scale of the challenge facing all individual Peel archiving projects or archivists.v On the one hand, especially in the eight years since Peel's death, the details of his career have been documented with increasing reliability, from the start of his radio career in sixties America (Rothenbuhler, 2007), via offshore pirate radio (Chapman, 1992; 122-131), to joining the BBC and his achievements thereafter (Garner, 2007). Yet this has only left a growing awareness of exactly how much of his work we now know is lost. Of the 5,651 regular shows Peel presented in his 37 years with Radio 1, the BBC only recorded and kept 1,178 (20\%), almost all of these after 1990, and most from after 2000 . In the last ten years listener donations of off-air recordings have added about 140 shows, bringing the BBC's total official holdings to just $22 \%$ of Peel's main work. The reasons for this huge gap are wholly 
understandable, and bound up in the technological context which governed what at any time the BBC could preserve. The Corporation has long wrestled with contentious issues in broadcast archiving such as selection, retention, preservation - and more recently, digitization - and access.

Today, and since 2008, everything broadcast on BBC national network radio is 'selected' for archiving, recorded digitally from the networks' play-out systems, kept for five years, and the expectations of archivists are that all of this final output will then be kept permanently, or 'retained' (Simon Rooks, BBC Multimedia Archivist, 6 December 2011 interview). This is a permanent continuation of a policy begun experimentally in 1999, when it was decided to record and keep all transmitted network programmes for five years, by asking radio production teams to burn their show onto disc or digital tape during transmission. This came just in time to ensure almost all John Peel's final shows from 2000-2004, were, unusually, recorded on R-DAT by his last producers Anita Kamath and Louise Kattenhorn, kept in a filing cabinet at Radio 1 until 2009, and, eventually and only recently, permanently retained by being ripped into the main digital archive. 
Citation: Garner, Ken. 2012. 'Ripping the Pith from the Peel: Institutional and Internet Cultures of archiving pop music radio', Radio Journal: International Studies in Broadcast and Audio Media, Vol 10 (2), pp. 89-112

Before the late 1990s however, things were very different. Only a small number of all programmes on all stations were 'selected' for the archive. From the launch of the Permanent Library in the Recorded Programmes Department in the late 1930s under Marie Slocombe, through to its renaming as the Sound Archive in the 1960s and beyond, cost, space and technical reasons meant only a very limited number of shows could be selected, recorded, then eventually further selected for preservation and retention, via the cutting of discs, or later, vinyl LPs, and eventually CDs (see Stewart, 1986; Stewart and Fees, 1996; Street, 2007; Archive Hour: Marie Slocombe and the BBC Sound Archive, 2007; Rooks, 2010). Most shows were presented live, and recording was regarded as not central to the BBC's activities. The criteria for selection were simple: a programme had to offer something out of the ordinary and exceptional, likely to be of interest and therefore re-use by future programme makers, in order to be selected, recorded, and get a place in the queue for possible permanent retention and preservation. The archive's primary function, as a 1950 internal memo put it, was 'to build up a storehouse of recordings for future use in BBC programmes,' which thereby also formed 'a collection of recordings which has wider historical interest'; but that the emphasis on the needs of programme-makers gave the collection a 
'concrete aim' and 'more practical criteria of judgement' than any more general consideration of preserving audio for posterity. Selection being core to the process, there had to be 'Selectors' to implement it, initially just two in the post-war years, rising to five by the 1970s (Rooks, 2010; Carpenter, 1996, p 367; Phil Lawton, former selector/Radio 1 Archivist, 24 June 2010 interview). It was 'mostly keeping stuff for spare parts' (Ageh 1 November 2011 interview). But by the end of that decade, only about 12 hours a week of all $\mathrm{BBC}$ radio output were being selected and added to Sound Archives. This was 'not nearly enough,' said an enquiry led by Lord Briggs (Report of the Advisory Committee on Archives, 1979).

What this perfectly rational policy meant for live, daily, popular and popular-music based programmes like Peel's - the everyday, the quotidian of radio - is obvious. They were not selected, recorded or retained. By their very ordinariness, DJ-presented shows of pop records and $\mathrm{BBC}$ sessions of light music recordings were consigned to oblivion by archiving policy, having by definition nothing out of the ordinary about them. The only exception came later in the 1970s, when the BBC sometimes recorded the total output of all national stations on one day a year, in what later came to be called 
'heritage' recording. Nevertheless, in 19 of the years between 1967 1989 when Peel was broadcasting at least twice a week, prior to some recent donations the BBC had no recordings of Peel's shows at all. There was one from 1975, one in 1979, and one in 1989 - out of a total he had presented live of not less than 180 shows in each of those years. Holdings only started edging up in the 1990s, reaching 51 shows in 1996. vi As the BBC archivist Simon Rooks acknowledges, this 'historic lack of attention given by the Sound Archive to pop and rock music', across programmes and prerecorded items, "had ensured that little of this output had been archived, with commercially and culturally important material being left unmanaged in producers' offices and even homes' (Rooks, 2010).

It's perhaps then not so surprising that it was the BBC's network controllers, producers and archivists specialising in pop and rock who were both the first in $\mathrm{BBC}$ radio to take control of preservation themselves, and later, the first to embrace digitisation as a new permanent method of ensuring it. The first solution to preservation of pop recordings was the establishment of the Radio 1 Archive in the basement of Egton House, the station's studios, in 1987, and the seconded-appointment of Phil Lawton from the main Sound Archive 
as a dedicated selector-archivist for the network, if only for two days a week (Garner, 1993: pp. 10-12, 195; Garner, 2007: p. 126; Rooks, 2010; Lawton 24 June 2010 interview). But excluding documentary series, at that time it contained few recordings of complete programmes, and mostly constituted live session and concert recording items, the Peel Sessions being the largest holding at 10,000 tapes, representing a quarter of the Radio 1 archive by the end of the century (King, 2001). By that time, an unannounced visit to the Radio 1 archive by the then BBC director-general John Birt in March 1998 (Garner, 2007: 184-186) had led rapidly to a plan to digitise the entire station archive. At a cost of $£ 2.5$ million, all 40,000 recorded items were digitised by 2002 , vii ready for the launch of the BBC's digital radio station 6 Music, which was designed to feature $\mathrm{BBC}$ archive recordings prominently in its programming.

The success of the Radio 1 archive digitisation pilot led directly to a new team, Preservations, being set up at BBC Maida Vale studios in 2000, with 20 expert audio engineers using their own customised software and hardware to bulk rip a mountain of $\mathrm{BBC}$ radio tapes, disks and other media, part of a $£ 56$ million, ten-year BBC project committed to digital preservation across all its audio-visual holdings until 2010 (King, 2001; Weaver, 2009; Digital Curation 
Centre, 2004; Rooks, 2009). That project has now ended and the Preservations team disbanded, but a minority of its staff continue its work on-demand (the BBC recognised in 2003 that migration of all its holdings to digital was a 10-20 year undertaking) at a large purpose-built facility in Perivale, West London, opened in 2011, which preserves and secures the entire audio and video archive from original wax cylinders, discs and tapes to digital servers - for the first time in one place (Bambury, 2011; Skinner, 2010; Kiss, 2010a).

Despite these advances, few scholars or listeners would have imagined it possible a decade ago that the $\mathrm{BBC}$ would create a new directorate, with a main board director, whose sole purpose was defined as maximising public access to the corporation's archives. But this is how digitisation, the internet, and innovations like the BBC iPlayer - allowing British listeners and viewers to watch or listen to programmes online - have changed the BBC's awareness of what is strategically and technologically possible in allowing access to its collections. Soon after Roly Keating, former controller of BBC2, was appointed the BBC's first director of archive content in 2008, he launched the Archives section of its website, releasing on to it selected dedicated speech-radio collections for permanent 
listening online in the UK - George Orwell at the BBC; Music from the Mersey: the story of pop music in Liverpool - and profiles of the staff and work of the archiving team (see, as above, Rooks, 2009; Weaver, 2009; Keating, 2011).

Welcome and innovative as these projects are, they do not mean scholars or the public will be able to search and listen online anytime soon to the totality of the digitised $\mathrm{BBC}$ radio archive, and especially not music programmes like Peel's, where copyright problems remain a major barrier. The scholar of twentieth century BBC pop radio history's only accessible documentary resource within the $\mathrm{BBC}$ itself remains a written archive, not a sound one (Scannell, 2010; p 38). Before the late 1990s the only records kept of music shows were paper-based, for promotional, legal or contractual reasons, preserved and available for study at the BBC Written Archives (Kavanagh, 1999, 2004): programme listings in the Radio Times; a typed list of musical items played, for copyright returns, known as the 'programme-as-broadcast' or 'PasB'; and the contracts hiring musicians to perform live or pre-record musical items. For music programmes such as Peel's, such documents neither provide the script of what he said, nor, obviously, any record of the momentby-moment verbal performative relationship between the presenter 
and the musical voices introduced. And when off-air show recordings do turn up, it emerges that the PasBs were not always 100 per cent accurate, with the sequence of records played sometimes altered, the odd track listed but not actually broadcast, and on occasion songs that were played missing from the PasB altogether. It's little consolation, but other developed countries such as the USA have similar problems: 'Post-1960 radio broadcasts are represented more sparsely in archives than is any other contemporary mass medium' (Brylawski, 2002).

Senior BBC authorities have been concerned about the issue of access to hearing the actual sound of the corporation's musical past for over 30 years. Asa Briggs' investigation into BBC archives realised that "wider access to the Archives might require changes in the contractual relationship between the $\mathrm{BBC}$ and its contributors' (Report of the Advisory Committee on Archives, 1979), and a few years later Mark Jones, head of BBC Sound Archives, said 'It's not easy to see how some of the copyright problems can be overcome. It's not easy to see how the viewpoint of the performing rights bodies and the performing unions can be taken into account while talking in terms of access to the kind of material that we have here' (Jones, 1985). 
But recent strategic partnerships between BBC Archive

Development and external bodies - as with the John Peel Centre project, for example - suggest a way forward. Most significant in terms of improving access has been the agreement to share digital archival assets with the British Library (Bunz, 2009), which among its holdings has thousands of its own recordings of $\mathrm{BBC}$ radio, including more than 2000 VHS tapes (VCR machines were once the only programmable broadcast recorders available) of John Peel shows from 1985-2000, which it is currently halfway through digitising, plus other rare BBC live music sessions (Andy Linehan, popular music curator, 29 June 2010 e-mail communication; Fargion, 2004). This reciprocity means in the not too-distant future scholars and members of the public alike might be able to visit the British Library at St.Pancras in London, book a listening booth, and listen to a vastly expanded digital collection of Peel shows. viii

Meanwhile, scholarship into Peel has been finding a different route to the past. Recent analyses of his career through his actual work his radio programmes, the music he played in them and what he said about it - have suggested his distinctive qualities lay in, variously: 'his radical act of prioritizing music as the primary code 
of his form of music radio'; 'discourses of authenticity' embodied in his career, taste, and contradictory public identity, his 'studied and career-long divestiture of the advantages of a public-school education and tones of Received Pronunciation'; a 'discourse of amateurism' characterizing popular music as 'ordinary' (Long, 2006); and a 'paradoxical persona' in his broadcast talk, 'multifaceted and shifting, ...amateur/professional, fan/gatekeeper' (Winham, 2008). But there is a further paradox of methodological necessity acknowledged by both these studies. None of their sources for his main broadcast work on Radio 1 are official. Neither used BBC archives for this purpose. For their primary sources of Peel's main Radio 1 programme, both Long and Winham were obliged to download multiple show running orders and illegal off-air programme recordings from the internet.

\section{JOHN PEEL LISTENERS: TAPING, SHARING, DIGITISING}

Long and Winham had much to choose from. The volume of off-air recordings of John Peel's BBC shows now available online is growing all the time. Including incomplete show extracts - normally not less than 40 unedited minutes of a two-hour show - a scan of the blue-highlighted dates in the Peel Wiki's calendar indicating shows for which audio has been recovered, suggested in 2011 that 
at least part of each of 1,475 shows was available (John Peel Wiki, 2012). This illegal archive owes its existence to the centrality in Peel's listeners' behaviour of taping the programme off the radio. As this study will show, while most former Peel listeners hung on to only a handful of their off-air tapes, dozens kept more than 150 tapes. Almost 100 listeners have each kept at least 50 tapes. Such dedication may represent a minority of a specialist audience, but the net result in captured radio otherwise lost, not officially archived anywhere, is substantial to say the least.

The John Peel Listeners Survey, a four-page, 38-question, 10minute, anonymous, untracked IP-addresses survey was set up online via surveymonkey.com to try to acquire quantifiable data on listeners' listening, taping and archiving practices and principles. ${ }^{\text {ix }}$ A final question invited any anonymous further comments up to 250 words on any aspect of the survey, to which 233 responded.x The results are undeniably biased towards active social media participants, constituting a self-selected sample wholly unrepresentative of the global population, but at the same time arguably a successfully targeted study of the desired specialist group. More than 750 responses were received in the first 21 days, 
rising to a total of 1,065 by the closure date, of whom $79 \%$ completed the survey. Key data about the respondents includes:

- More than $80 \%$ over 35 years old

- Almost 85\% male; $83.5 \%$ British; $76 \%$ live in the UK

- More than 75\% university/college degree-educated or higher

- $\quad 71 \%$ employed, 17\% self-employed

Most importantly, however, when asked to define the nature of their relationship with Peel from ten options, more than $68 \%$ chose 'regular listener', defined as listening at least once a week during those years when they were tuning in - and $43 \%$ said they were such a 'regular listener' for from 3 to 10 years, and $25 \%$ for up to 20 years. Only 5\% had never listened. The respondents thus represent a strong sample of Peel's loyal following.

Nevertheless it is still a surprise to find that even for this committed audience, the most common kind of recordings they made or acquired during Peel's lifetime related to his show was their own private off-air recordings of his programmes, with almost $80 \%$ saying they recorded the show (see Table 1). 


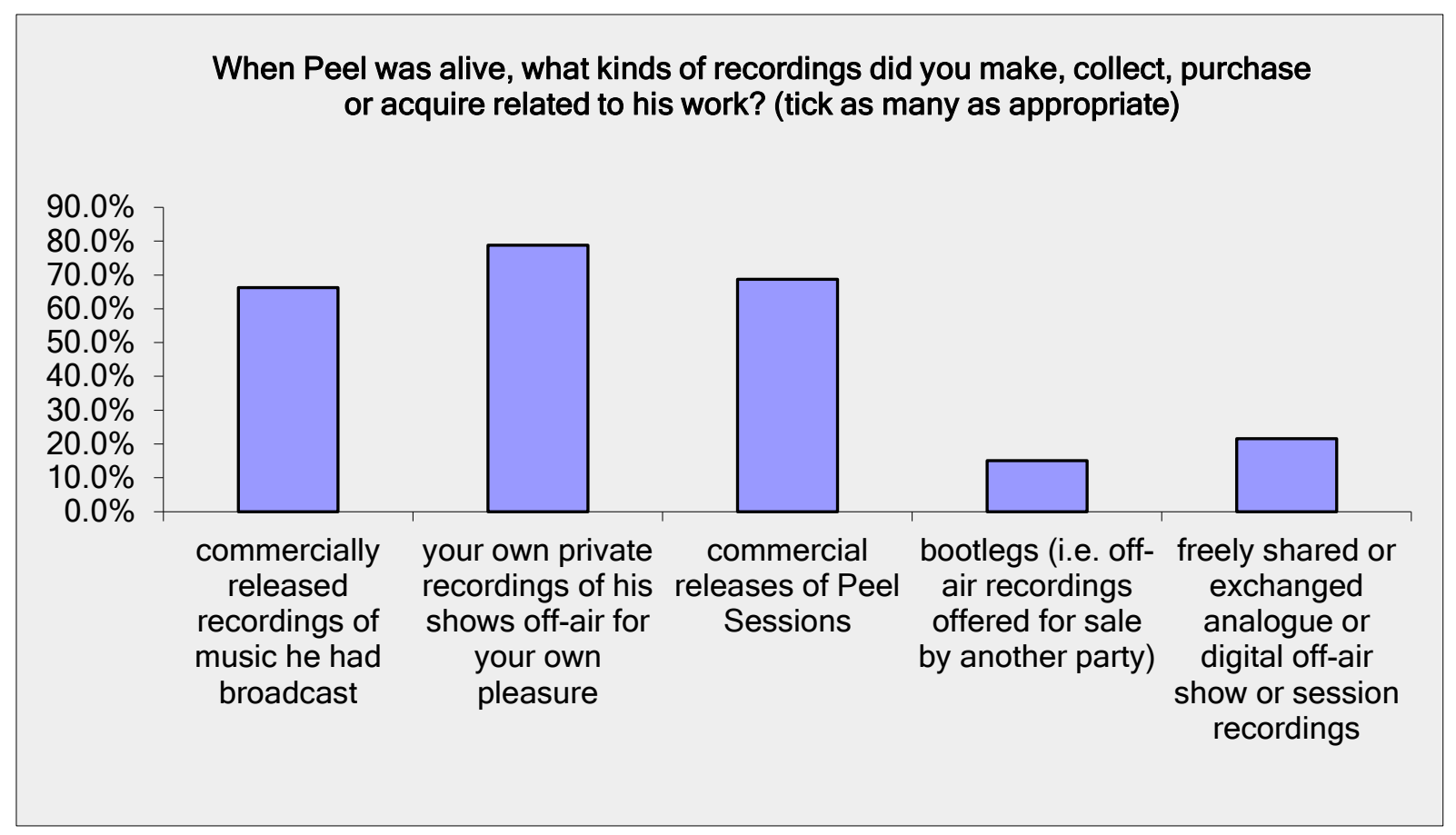

Table 1: Listeners' recordings related to Peel

By comparison, only a tiny minority bought bootlegs (15\%). The fact that this off-air show taping was central to their listening, dwarfing even their buying of records he had played (68\%), is explained by a common thread of comments made in the final open question box of the survey, each line below from a different respondent:

For me, taping tracks from the Peel show was a great way to hear and get to know new music.

I taped every Peel show for years to listen to on my commute. 
As a postman I used to record Peel's shows while asleep and listen to them on a Walkman while at work.

I was a 'pauser' taper while at university, notionally studying.

We used to swap tapes of Peel shows at school in the 70s.

In the days before the internet and living in a rural location with a very poor local record shop recording the music directly from his show was how my friends and I started our musical collections.

I used to record music from Peely's show during the punk era as I couldn't afford to buy many records.

I used to wait until the sig tune at $10 \mathrm{pm}$, put a C90 in and go to the pub.

As a teenager with a crude mono tape recorder I listened when I was supposed to be asleep with my finger on the record button.

These comments suggest something else that the survey confirms elsewhere: almost $69 \%$ said their taping was 'selective' (ie. not continuous), recording only specific songs with finger-on-the-pausebutton. For most, taping was also a relatively modest activity, producing less than 50 tapes of occasional shows (see Table 2): 


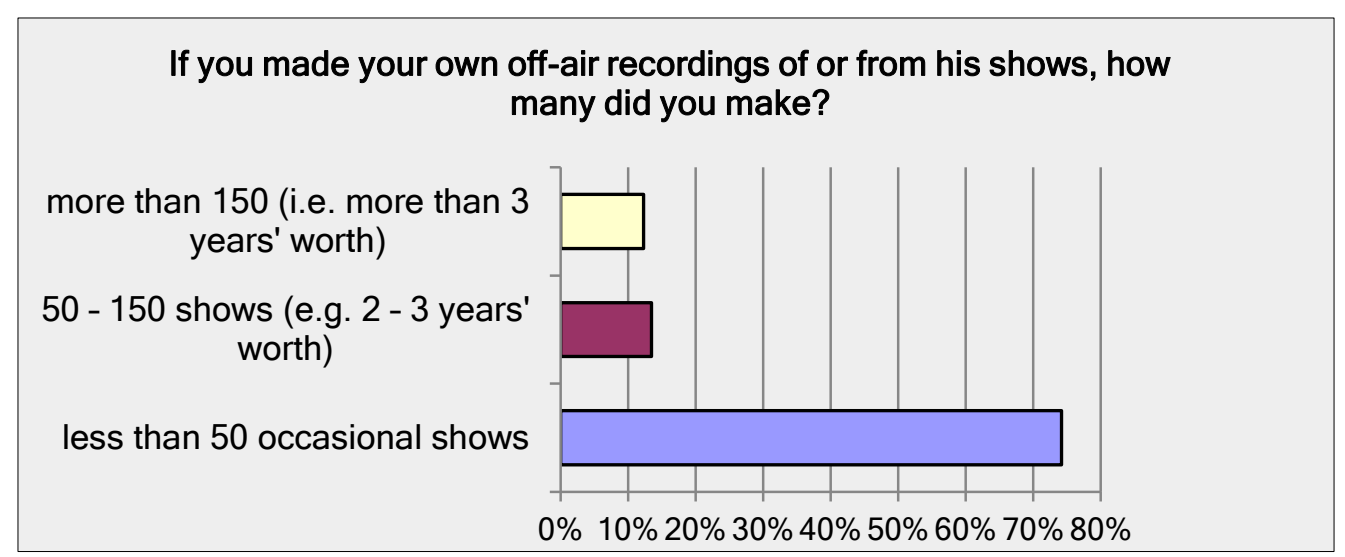

Table 2: Number of off-air Peel show recordings made.

So taping the show, though remembered intensely, was for most either limited in extent, possibly by the duration of their listening (eg. less than three years); and limited by being selective at time of recording. Most listeners did not keep many of these tapes, either: 


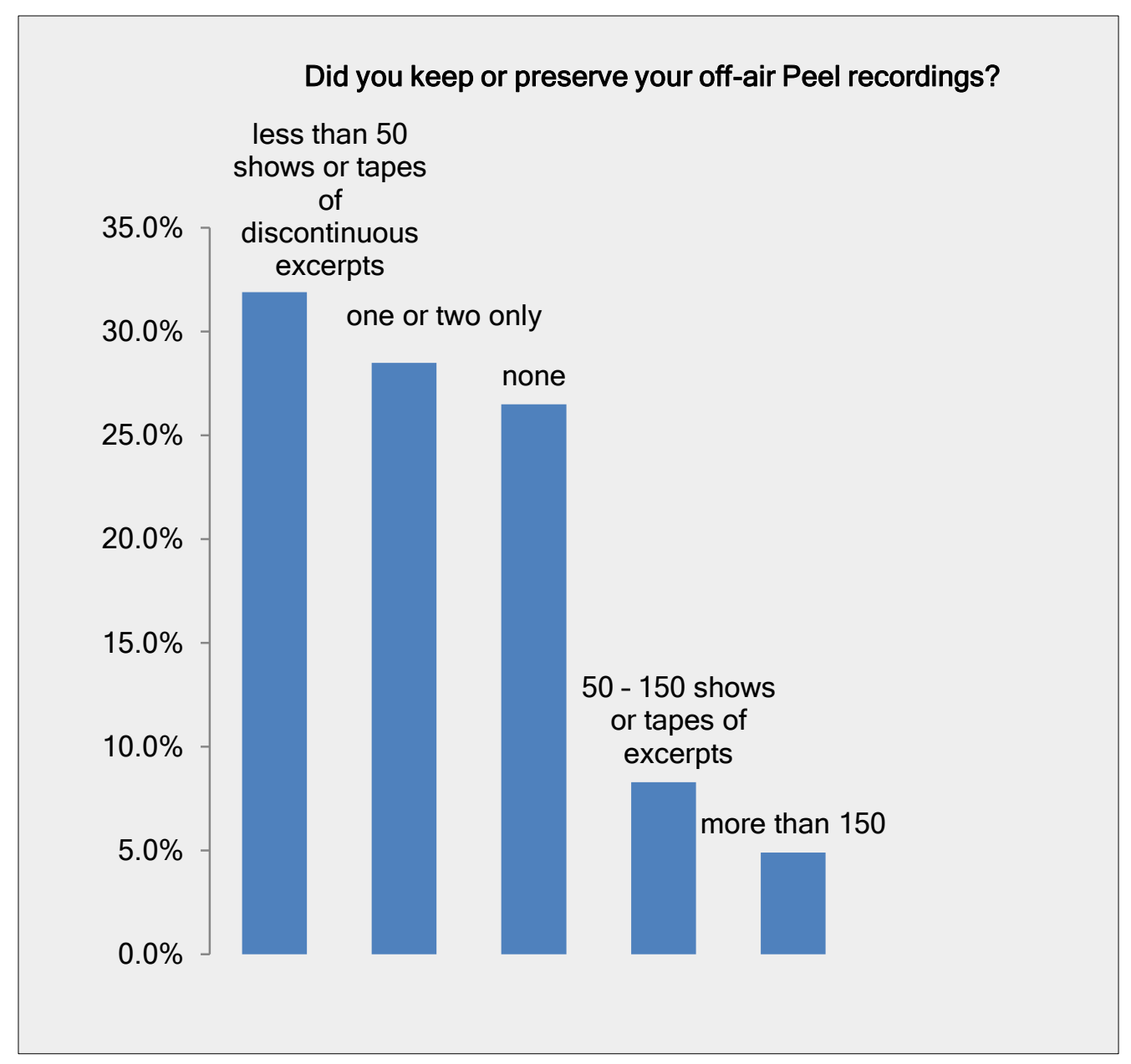

Table 3: Retention of off-air Peel show tapes made.

Almost $87 \%$ kept less than 50 tapes, almost a third of them none at all. Even those who did keep some tapes have mostly done nothing with them, either before or after Peel's death (See Tables 4 and 5): 


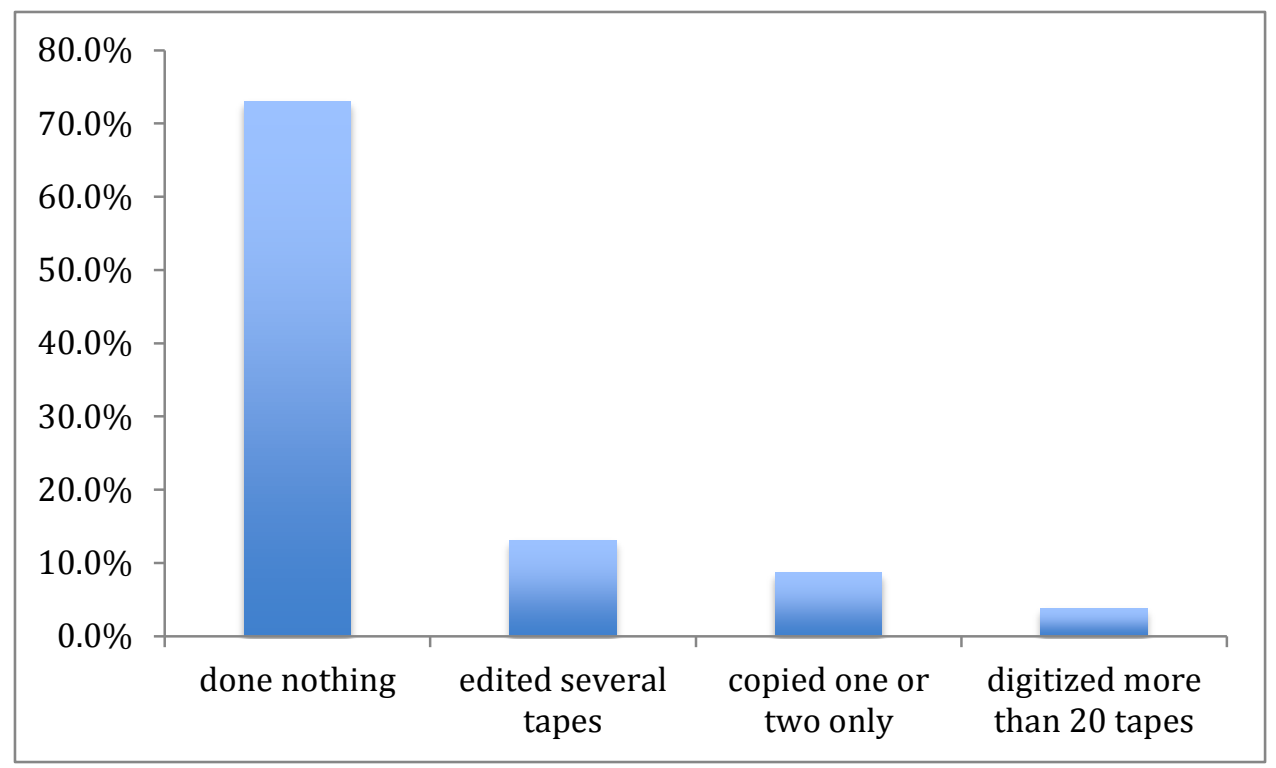

Table 4: Did you preserve your tapes before Peel's death in 2004?

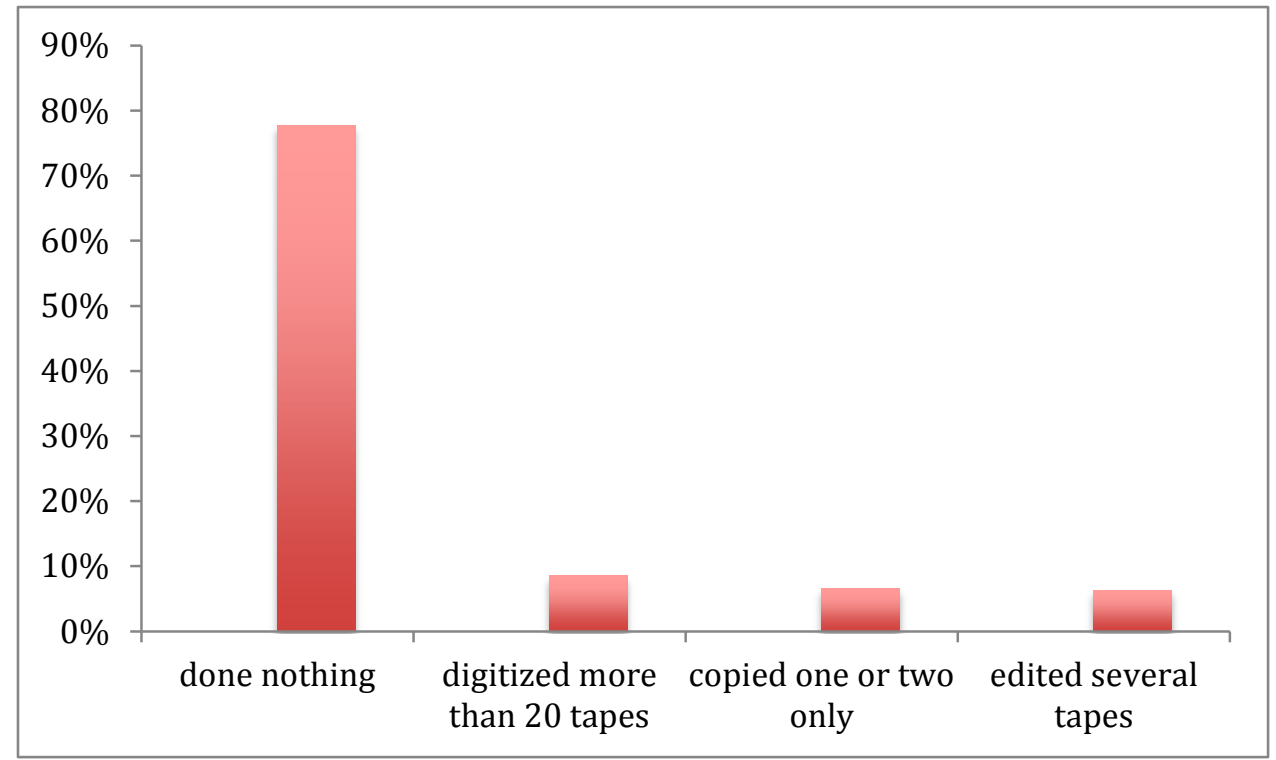

Table 5: Have you preserved your tapes since Peel's death in 2004 ?

It also seems that almost half of these internet and social-media aware Peel listeners (47\%) have nevertheless not downloaded any 


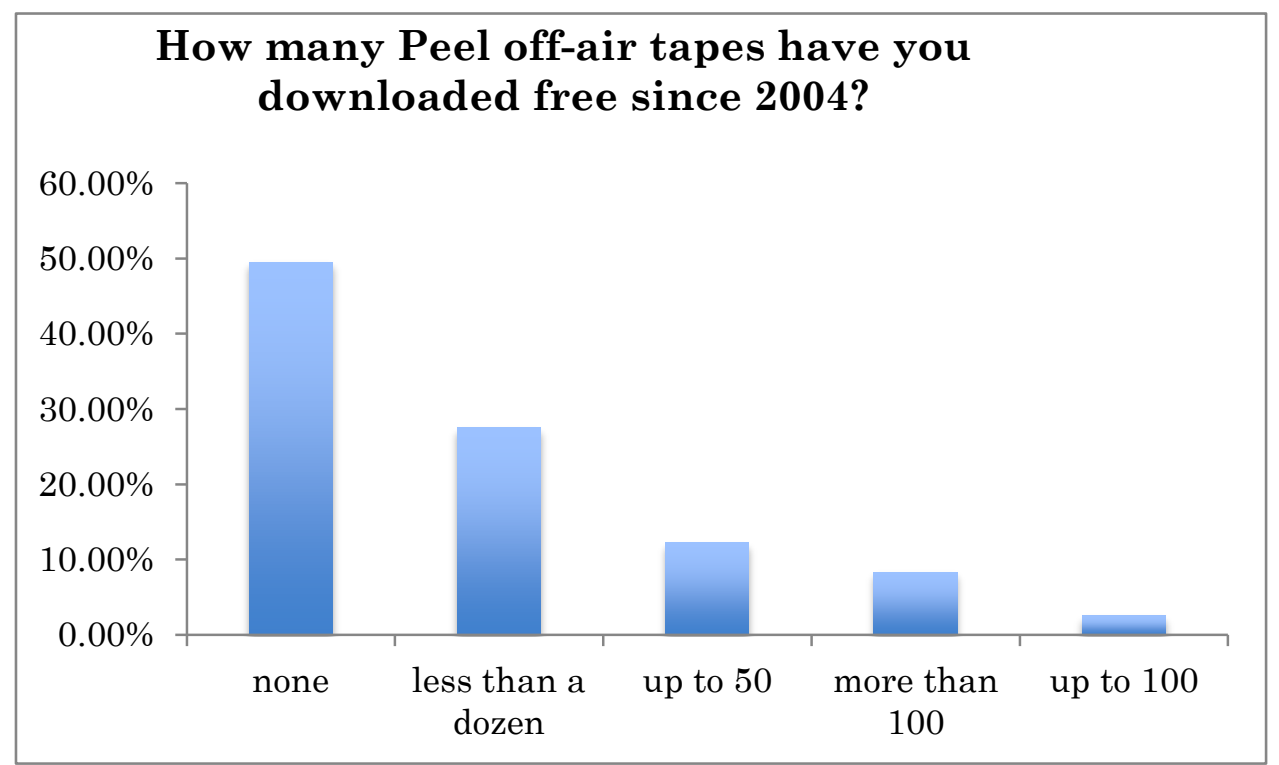

Table 6: Downloading of Peel show tapes since his death.

All this suggests that the taping, preservation, digitising and sharing of continuous/unedited private off-air tapes of Peel's shows is confined to a very small minority of his regular listeners. But the really interesting numbers are hidden in what this minority-of-aminority practice means in terms of actual surviving recordings. A careful look at the smallest rectangles in these histograms suggests the following astonishing results of this taping and preservation activity: 
- $12 \%$ (89 respondents) taped more than 150 shows

- More than $30 \%$ of all recordings were continuous/unedited.

- 5\% (37 respondents) have each kept more than 150 tapes.

- 8\% (63 respondents) have each kept between 50-150 tapes.

- More than half have downloaded some digitised off-air shows.

Even on a conservative estimate, these responses suggest that this sample of listeners alone could collectively possess 2,600 continuous or unedited off-air tapes of John Peel shows, a third more than the entire official BBC archive. There is other evidence that suggests this is not an entirely fanciful analysis. When asked if they had engaged in any tape preservation activities, 8.5\% (65 respondents) said they had digitised more than 20 of their own off-air tapes; but $3.7 \%$ (32 respondents) said they had digitised more than 20 such tapes which were not originally their own. It is these few dozen listeners who have since 2008 helped collectively reconstructed more than 1,300 John Peel Shows, each either complete or more than half complete, as reported and documented online via the Yahoo group. But this now wellestablished collective practice was simply triggered by a group response to one unexpected opportunity. 


\section{THE PEEL TAPE PROJECTS: PRACTICES \& PRINCIPLES OF LISTENERS’ COLLECTIVE, DISTRIBUTED RADIO ARCHIVING}

In June 2008 a member of the Peel Yahoo group spotted and circulated the news that someone in the English west country was offering on e-bay his box of roughly 400 off-air tapes of the John Peel show from 1978-1987, in return for the highest bid which he would donate to a local BBC charity. Within days a decision was made for the group collectively to pool resources and attempt to 'secure the archive for posterity', as the lead bidder of the group put it. More than 50 members, including the author, contributed cash, and in July the group's bid of $£ 529$ was successful. The tapes, immediately named 'The 400 Box' (400 Box, 2011), were collected and catalogued by a member living near to the seller (each tape given a number, prefixed by $\mathrm{T}$ for tape), then posted, in batches of 20 , to ten volunteer digitisers from the group around the world, with spare cash raised by the collective bidding donations paying for postage and packing. Within a little over two years, almost the entire box had been ripped, dated, documented, and where possible complete programmes reassembled by editing together sections on different tapes that had become separated. 
Even as this project was getting under way, it inspired similar collective digitisation projects, such as the 500 Box (500 Box, 2011), and the SL Tapes (SL Tapes, 2011), a collection of 623 tapes. There are other smaller and individual projects in hand. They are united by a few simple, shared practices and principles which emerged and were agreed rapidly during discussion in 2008 on the Peel Yahoo group regarding how to approach the 400 Box Project.

\section{Technical standards: digital audio file formats and file naming}

No matter how seemingly poor the audio quality on any tape, rippers/digitisers make a lossless, uncompressed version for preservation and master-show reconstruction purposes later, mirroring the BBC's policy. Digitisers decided on the FLAC format, as most commonly available in various software packages and which had presented fewest problems to those previously engaged in such work in other contexts, but with AIFF or WAV acceptable if a ripper's particular set-up did not support FLAC. These uncompressed versions are only shared between the named digitisers contributing to any specific project. At the same time, a compressed mp3, normally encoded at between 160-192 kbps, is made for more widely sharing among the Peel listener community, 
via various bulk file upload sites, private ftp-address servers (with password access only), and most commonly in 2011 a shared server (also with password access only). Although not always observed, the commonly agreed file-naming practice, followed by the format suffix as appropriate, is the form: Peel / year-month-day show-part / tape project number / session guest(s), eg. 'Peel 1978-10-25a T047 Fabulous Poodles, Metal Urbain'. This enables all Peel show files to be found in the same place, and appear in chronological order in folders and directories.

\section{Distributed archiving: Multiple copies aids preservation}

There has been much intermittent discussion online about whether all recordings from all tape projects could not be made available conveniently in one secure online place, a question most often raised by new members of the online Peel Yahoo group. This is rapidly rejected for any of three common reasons. First, it is recognised that the making of both the original off-air tapes and any digitised versions of them is technically illegal under international copyright laws, and although pursuit or prosecution of these projects may be unlikely, it is prudent not to expose any one individual, blog, website, or corporate entity laden with such illicit artefacts to the scrutiny of the copyright protection agencies. 
Second, there is the rationale that distributing copies to multiple users secures preservation, as famously articulated by Thomas Jefferson 220 years ago: 'a multiplication of copies', is the best way of putting what remains 'beyond the reach of accident'. With digital files, this policy has gained urgency by the propensity of servers and hard drives to fail. And as revealed in comments in the Survey, given yet further ethical self-justification by the fact that the BBC has not always in the past preserved these recordings themselves:

The BBC are notorious for dumping important programmes so unofficial archiving is vital.

If the general public has the will and capacity to help store these programmes for future listening then they should be encouraged to do so.

It is always worth having multiple copies or versions of a resource of interest to a wide community. If the $\mathrm{BBC}$ lost its funding or a vital server blew up, where would the archive be then?

The final agreed reason for wider distribution of compressed mp3 files across individual members' computers, servers, download 
services and hard drives is it is this that enables much eventual archival show reconstruction. Members and digitisers do not know what else is out there until someone shares it, and as the sample posts from the Yahoo group at the start of this article attest, frequently fragments from different individuals' collections or various projects come together to aid show reconstruction.

\section{Non-Selective: Cultural value claimed for all surviving tapes}

The very names of the tape projects tell the story here. All 427, or 530, or 623 tapes (400 Box, 500 Box, SL Tapes: 2011), for example, will, eventually, be digitised. The notion that the ripping community might decide not to bother with, say, preserving another 10 shows that turn up from 1979 because the 400 Box has already completed more than 100 (about half), is inconceivable. Digitisers will not 'select' the best examples from a collection, but rather preserve everything they can. The only exception is when the occasional tape or cassette side in a project is found to contain 'no Peel content', when it is set aside, but even then not always.

\section{Recognition of the $B B C$ as appropriate primary repository}

At the conclusion of each major project, it's agreed that the lossless FLAC versions will be burned on to DVD-Rs and offered to the BBC 
Archive as a donation. The original tapes are returned to the original taper. One taper wanted to donate his hundreds of cassettes to John Peel's family, but was persuaded they were unlikely to be interested.

\section{Financial exploitation must respect copyright holders}

Rippers and survey respondents broadly agree that no-one involved should make any money from these tape projects (see table 7):

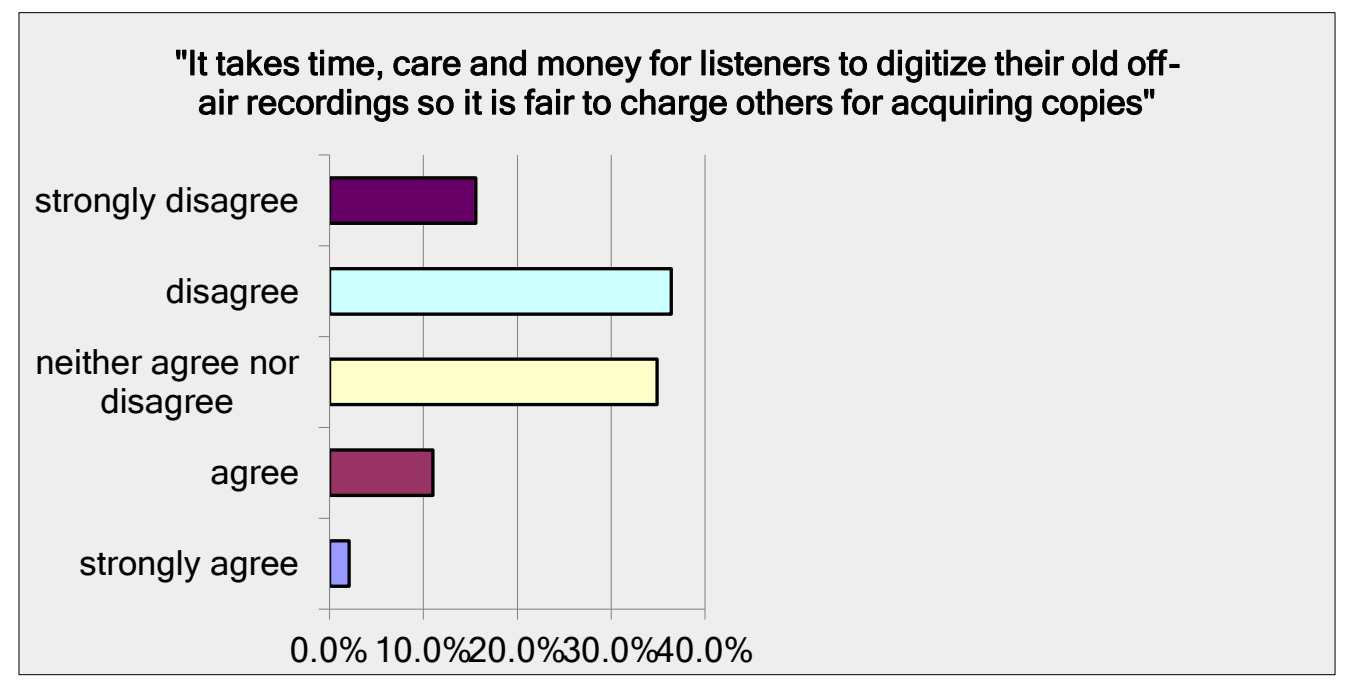

Table 7: Charging other listeners for copies/files

Although almost a third are undecided how to respond, only $13.1 \%$ agree or strongly agree. Openly bootlegging, publicly offering for sale online illegally any results of the projects, is condemned: 
I think it's important that swapping is a free traffic and not about personal profit.

I abhor anyone profiting from any recordings.

If someone is charging you to download something that has never belonged to them, that is obviously not on.

There are also strong opinions that any eventual, official commercial exploitation of show tapes should respect copyright holders:

I think sharing is fair if the shows are not commercially available, but if people are making money out of selling them then so should the copyright holders.

As Peel supported budding and unfashionable musicians, I think that they ought to be remunerated for the copying of their work.

I am a copyright owner. I don't object to "casual" copying, even if it infringes copyrights (i.e. individual people copying a radio show for their own personal use). However, I am strongly against anyone making money illegally out of someone else's intellectual property.

I do agree that artists should be rewarded for their work, and 
I have never bought, or sold, a Peel recording, except for official releases.

These views are also reflected in the strong welcome given to the idea of an official BBC sessions and concerts downloading/ purchasing site proposed some time ago by BBC Worldwide, the BBC's commercial arm (O'Carroll, 2008), but which has yet to launch (see Table 8):

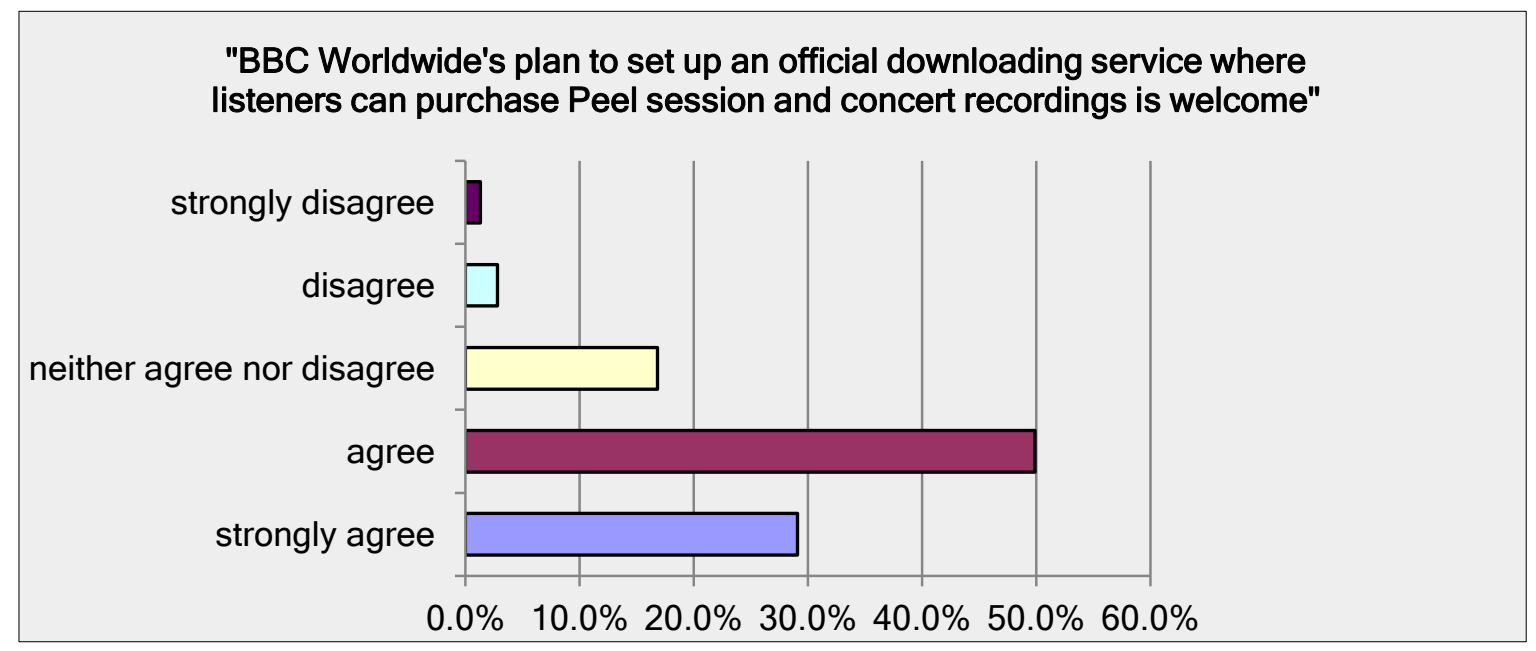

Table 8: Response to proposed official session/concert tracks download site.

But at the same time, response to another statement indicates that respondents believe the rights of copyright holders do not constitute the only cultural value latent in off-air recordings, and that 
listeners' own archival work by implication has an equivalent, if as yet unarticulated, legitimate public value (see Table 9):

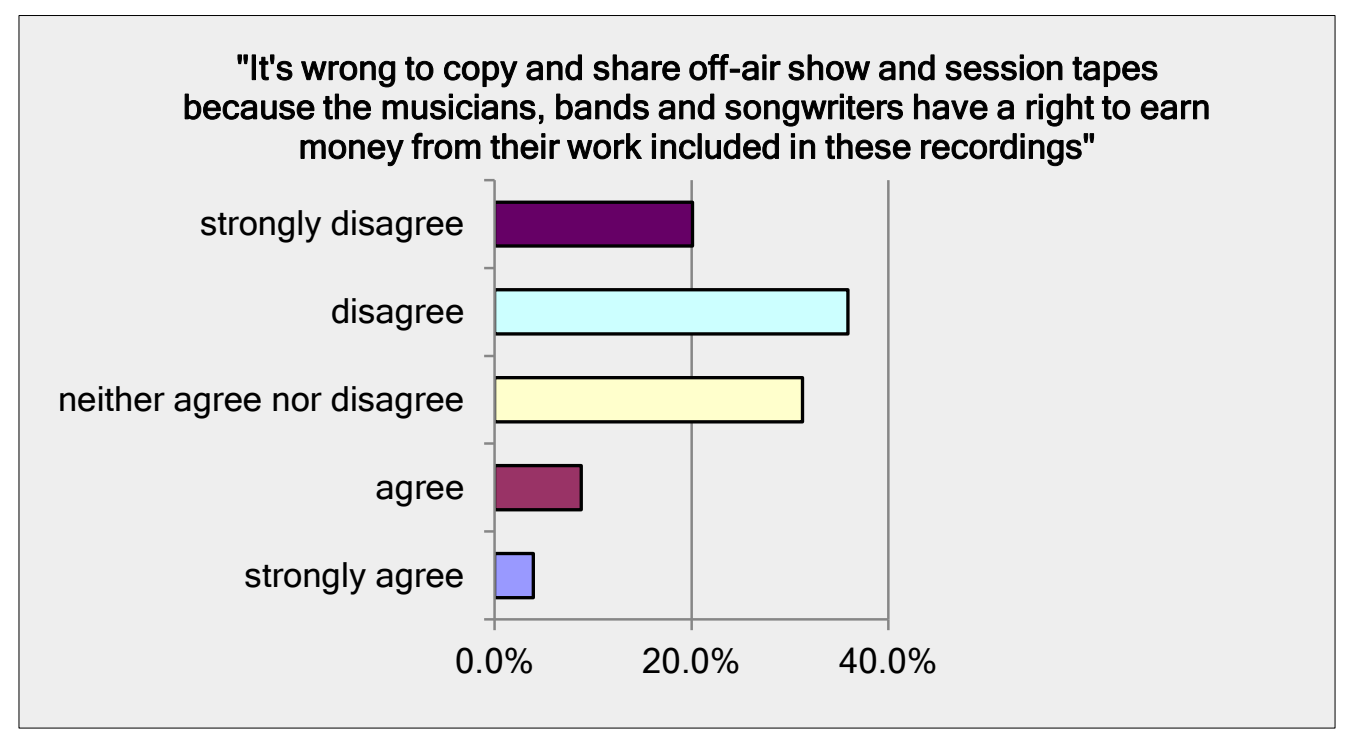

Table 9: Sharing v copyright holders' rights

\section{Sole objective is to develop a public, free, accessible archive}

The additional, supplementary value to that of copyright holders

Peel listeners are asserting, is simply that the totality of his programmes which these projects are reconstructing represents a public, cultural asset that should as far as possible be preserved and made freely accessible. The strong agreement that these projects are listeners' way of helping preserve his work (see Table 10), and are creating an archive that would otherwise not exist (see

Table 11), is, as revealed in respondents' comments below, forged 
out of a combination of: strong feelings that Peel's legacy belongs to the people; that only listeners can do this archiving; and that Peel's pre-eminence justifies the preservation and public accessibility of his work 'in whichever way possible':

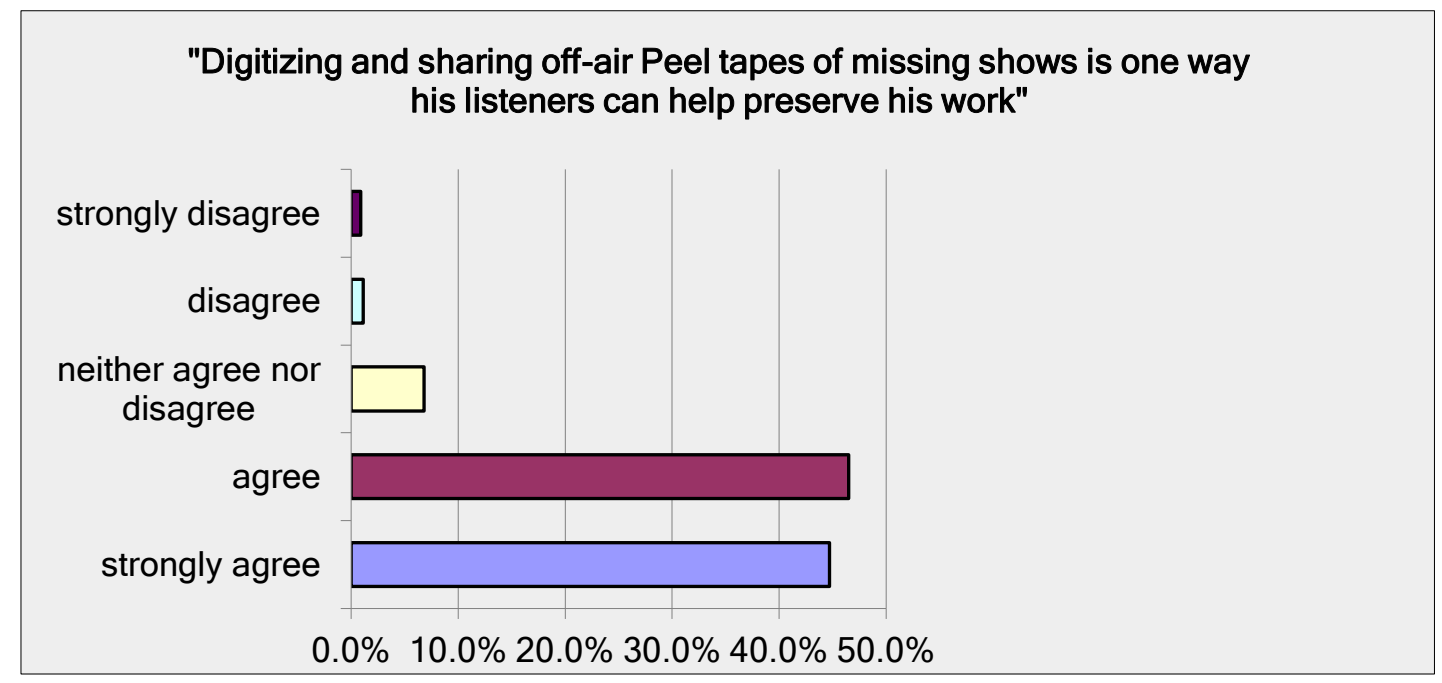

Table 10: Digitising \& sharing is listeners' contribution to preservation.

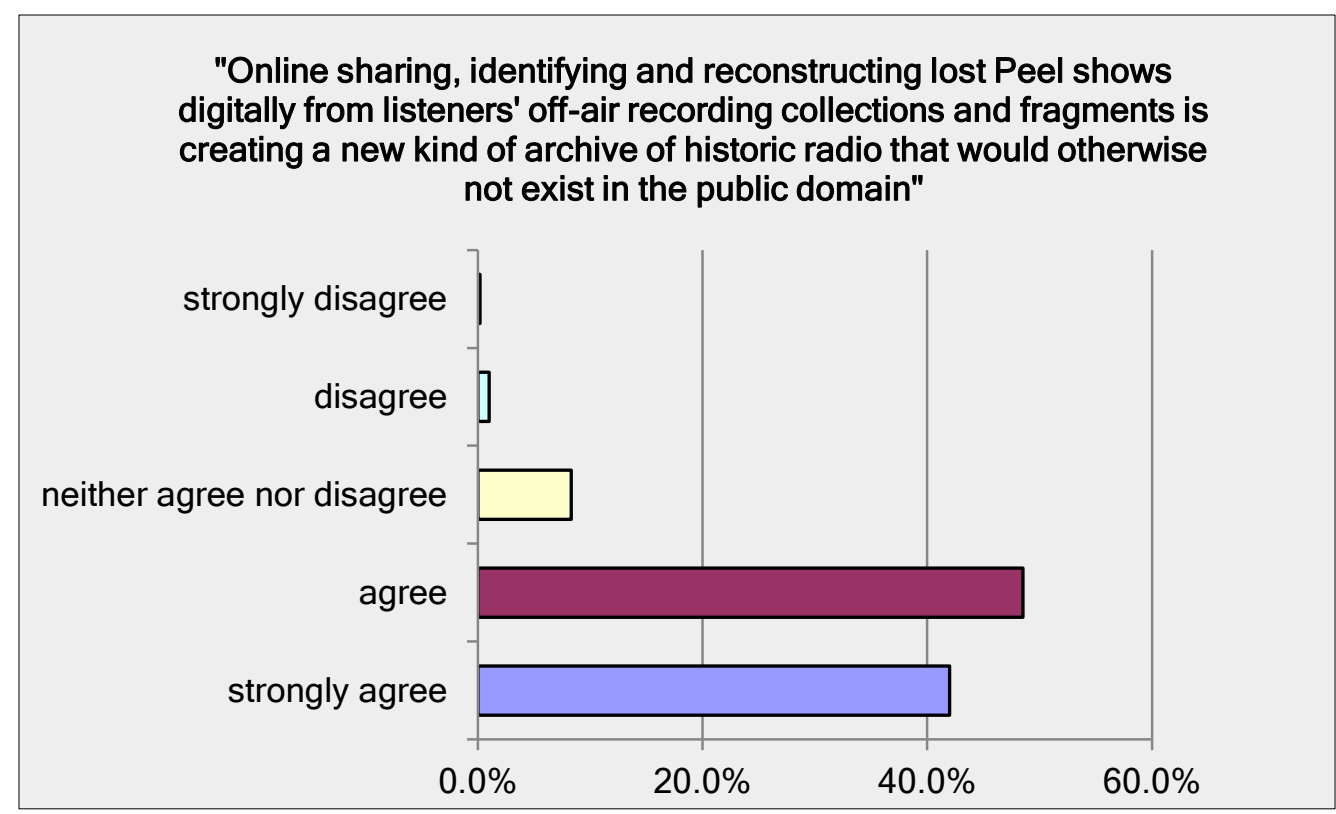


Table 11: Listeners' archiving creates a new public archive

Peel belonged to the people, it is only right that the people should appoint themselves as collective curators.

If we don't do it, and do it fast, it would be lost.

I realise I could do more but I would hope that by uploading some of my Peel tapes, despite their fragmentation, I am at least adding to an archive that will be incredibly enriching in the future.

John Peel is probably the most important non-musician music chronicler in the history of modern music and all of his contributions should be preserved for the benefit of future generations.

I view the old shows on the internet as an historical archive and not as a source of free music.

What listeners feel the BBC's role should be, relative to this crowdsourced archiving of their own, is suggested by their responses to two final, oppositionally-posed opinion questions in the survey (see Tables 12 and 13). 


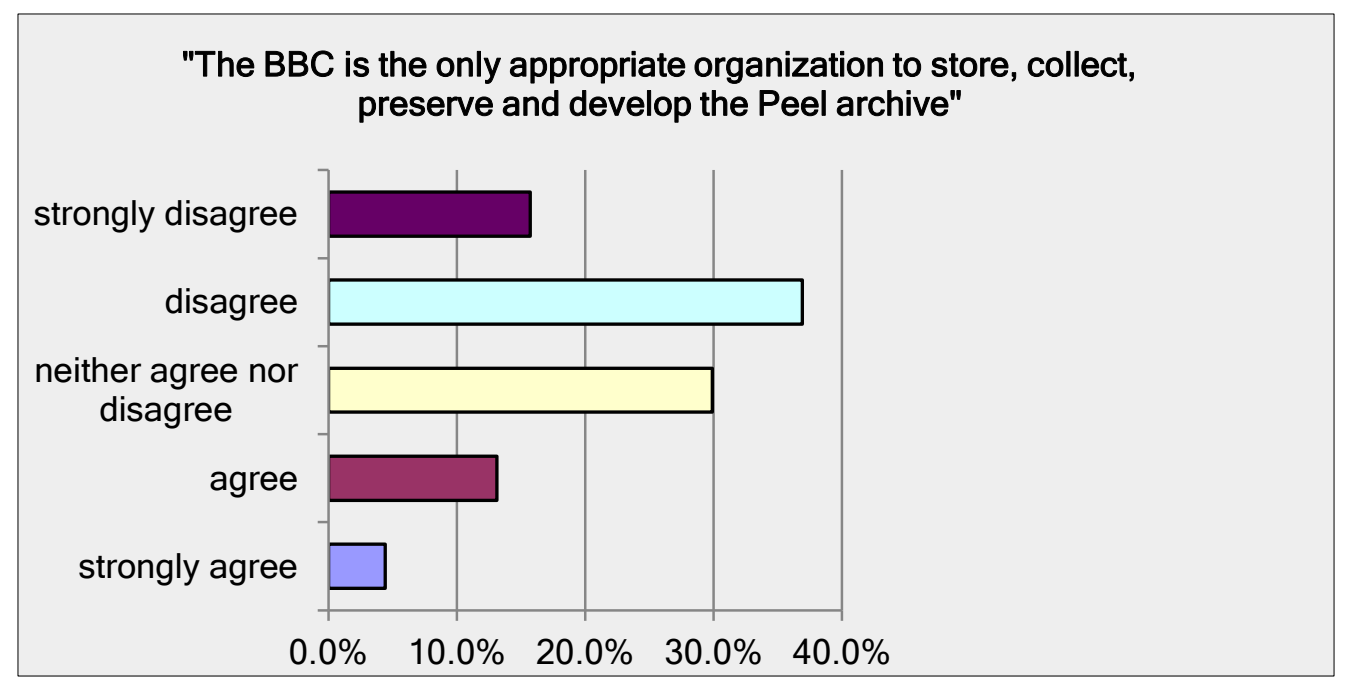

Table 12: The BBC as sole archivist organisation.

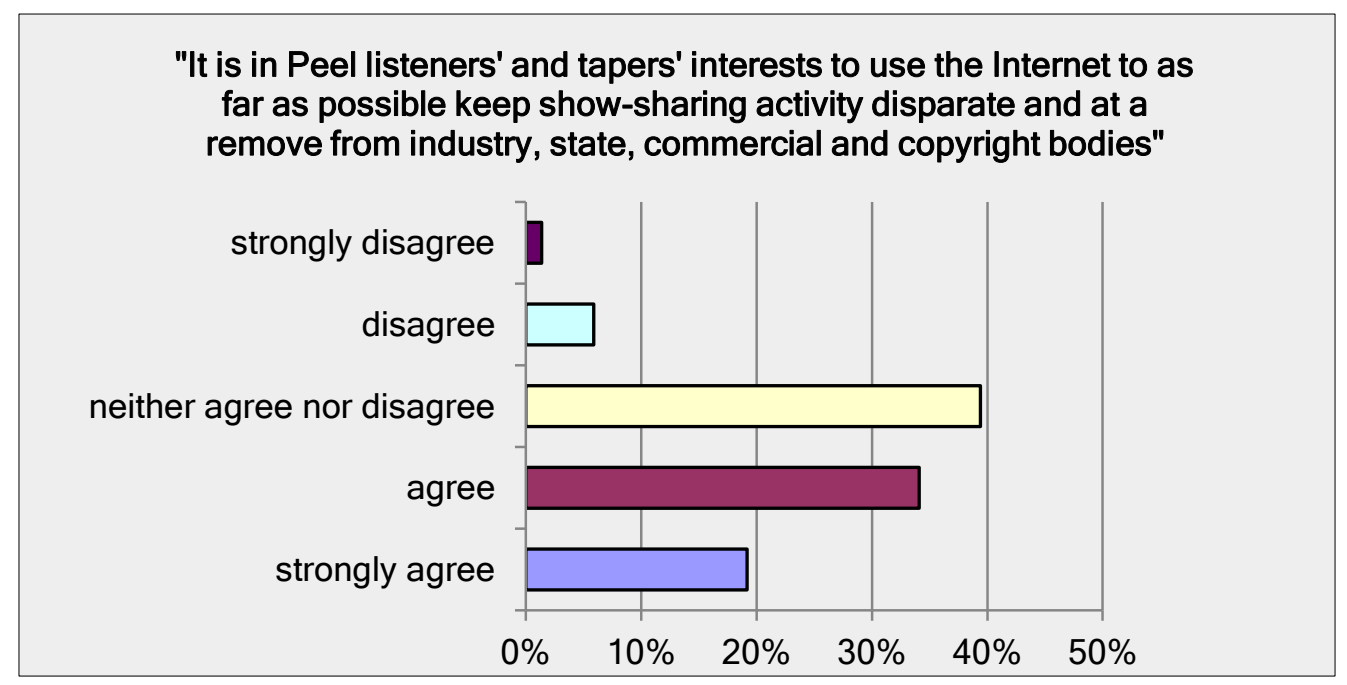

Table 13: Listener archiving independence.

While a narrow majority believe that the $\mathrm{BBC}$ is clearly not the sole legitimate archivist, almost a third are undecided and almost a fifth disagree. A similar narrow majority believe it is in listeners' interests to keep their archiving activity at a remove from the BBC, 
record companies and copyright agencies, but a large minority, 40\%, are undecided. What to make of these responses? The final comments offer some suggestions. It's true a handful of respondents are highly critical of the BBC, distrustful of what they believe, with perhaps some justification, to be the failure of the BBC to respect Peel's work in his life and his legacy after his death. But they are not representative even of this vocal minority of the specialist community. There is a larger group of pragmatic and thoughtful comments on what the relationship between listener-archivists and the BBC should be:

I can't imagine the $\mathrm{BBC}$ have the staff, resources, time or the same level of interest/enthusiasm as fans to do the job properly.

Most filesharers giving their time to such projects at the moment would willingly continue to do so, possibly more enthusiastically under the auspices of the BBC, or some university or library body.

Good to share to build up a complete archive. I think the archive should be developed by the BBC but should be available free to access (not download).

A full public archive of Peel shows would surely be an 
invaluable resource in terms of music history, and think the BBC should make every effort to try and make this available in some form.

It is welcome if the $\mathrm{BBC}$ are aware of the cultural value of Peel's work, but they cannot be trusted always to understand niche markets or the ritual transmission of culture, and should not have a monopoly on this important piece of our cultural heritage.

Internet sharers "good", Corporate/BBC/State "bad", is a little simplistic. We just need to find the right balance.

It seems to be recognised that ideally the $\mathrm{BBC}$ should have some role in the development of this core objective, the online creation of an accessible, free, public archive of Peel's broadcast work, but on current evidence, listeners feel they have to press ahead with their own efforts, and just hope the BBC catches up, despite its lack of dedicated resources.

\section{Archival labour for Peel is a voluntary, collective vocation}

Resources - that is time, labour and equipment - are something, however, that listeners have a limitless supply of, as far as Peel's work is concerned. As comments above show, the tape projects are 
conducted in a largely altruisitic spirit of mutual dedication to a cause. Not entirely, though, because one of the motivations, obviously, is to have the pleasure of hearing lost old Peel shows. More than 56\% agreed or strongly agreed with the statement 'I download digital recordings of Peel's shows and sessions because I want to hear programmes I missed or could not possibly have heard at the time', and almost 90\% agreed or strongly agreed that 'If people download and listen to old Peel shows, they are likely to hear music they do not know and go on to buy it'.

But the tapers share their tapes for free; members of the group fund the costs of tape distribution; and give up many hours of their time voluntarily and unpaid to documenting, dating, digitizing and sharing recordings and track listings. Only one respondent described this discourse of shared archival reconstruction as 'selfserving rationalization of illicit activity'. Far more common were statements like that of the respondent who said: 'The degree of goodwill shown in sharing these shows reflects how much he still means to us and how important we feel his contribution to music was, and still is'. 


\section{DISCUSSION AND CONCLUSIONS}

In some ways, the practices and principles of John Peel listeners involved in these online, collective digitisation projects would appear to have much in common with those of digital photographers. The key issues and sub-headings in Spurgin's persuasive study (2011) of how photographers agree online about their practices are replicated almost exactly here: 'File naming and Folders; Make Data Self-Documenting; Suitable Formats and Software; Backup your Files; Look After your Hardware; Be Aware of Intellectual Property Rights'. The principles of personal collection management appear strikingly similar across digital visual and audio media, with a key difference being that photographers are protecting their own latent rights, rather than making a judgement on how best to respect those of others. Crowdsourced digital archiving, however, as practised by Peel listeners, only finds a possible equivalent in the celebrated recent work of ravearchive.com, a Chicago-based group's online pooling and digitising of off-air rave DJ mixtapes from the 1990s (Nasaw and Danzico, 2011), though with minimal metadata: many mixes lack a date, and almost all make no statement on their provenance or source. By contrast, in this respect, in most of their principles and practice, Peel listener archivists have more in common with BBC 
archivists, from working on Peel tapes as a dedication to something above and beyond the day job, through audio standards of lossless digitisation, to encoding accurate metadata about the resultant files within the file names themselves.

Is the BBC Archive interested in the results of the Peel tape projects? On the one hand, the BBC neither has the resources nor the will to go out and try and get copies of every missing programme. But if an off-air recording provides an artist's missing Peel Session recording, they're very interested. The main criteria applied to their 'archive recovery' work when offered donations of potential importance for posterity are simple: is what's on offer documented and dated? Is it complete shows or items? And is it at a certain basic, reasonable sound quality? On these standards, it would appear much of what's been done might be of interest, because it's the listening and documenting time that is at a premium for BBC archival staff. 'Whereas if someone offered us 100 undocumented reels today, we'd have to say sorry, no, really,' says archivist Simon Rooks (Rooks 6 December 2011 interview).

There is as a consequence of these practical matters an unfortunate, accidental continuation in the archive and its development, of the 
institutional privileging of certain kinds of cultural, format and network-specific radio programming over others. It's a wonderful thing the BBC has now put online every episode of Melvyn Bragg's Radio 4 history of ideas programme In Our Time, and every episode of Desert Island Discs going back to 1990 - all of which it selected and retained at the time - even with the records chosen edited down to 30-second extracts. But that's not going to be possible for Peel's shows. Development is hindered by two things, according to Tony Ageh: the patchy holdings, which would make any attempt to make available what's currently held 'unsatisfactory' ('most people think they'll find every programme in there, nicely labelled'); and the external commercial and copyright pressures on the BBC's own new-found cultural, public aspirations for its archive:

There are four or five people who have been too vociferous in the mix, and I don't want to name them but we all know who they are, and they have swayed us away from an organisation like the BBC saying, actually we've got so much of value that would be genuinely important to give back to academia, to research, to education, to schools, to the public, to each of us as an amateur historian in our own right, or as a storyteller, or just as somebody who is creative, that the 
amount of money The Undertones are losing out of this, is not the point (Ageh 1 November 2011 interview).

Even so, he believes that debates around residual rights can, if not disappear, at least 'change their hue' once an entire collection has been digitised. This is a part of the same cultural, critical mass argument behind the partnership projects currently being developed by the Archive as part of the Digital Public Space initiative (see Ageh, 2011; Berger, 2011; Thompson, 2011; Kiss, 2011). The more examples there are of powerful agreements between elite public institutions - like the BBC, BFI, British Library, British Museum, and British Universities Film \& Video Council, for example - to share freely specific, complete sections of their cultural holdings, the weaker will become the engrained forces of opposition centred in other corporate and legal bodies. Or so the thinking goes. The challenge for the BBC Archive, in the face of the collaborative online digital archiving achievements of Peel's listeners, is to contemplate how to negotiate a new kind of partnership - and create one that would have real influence - with a crowd. The good news is the crowd and the external crowdsourcerto-be are broadly agreed on the principles, practices and public good arguments behind preserving Peel's work. Public broadcasters and 
Citation: Garner, Ken. 2012. 'Ripping the Pith from the Peel: Institutional and Internet Cultures of archiving pop music radio', Radio Journal: International Studies in Broadcast and Audio Media, Vol 10 (2), pp. 89-112

their publics everywhere might discover common purpose in such a distributed approach to reconstructing their shared lost past. 


\section{REFERENCES}

Ageh, Tony (2011), 'The Value of Memory', in A Prix Italia Conference, Telling History: The Art of Television and Radio testimonies and collective memory, Torino, Italy, Wednesday 21 September, also downloadable from: http://www.bbc.co.uk/blogs/aboutthebbc/2011/10/we-tellourselves-stories.shtml. Accessed 20 November 2011.

Archive Hour: Marie Slocombe and the BBC Sound Archive (2007), BBC Radio 4, 1 September, 20:00-21:00, now also at http://www.bbc.co.uk/archive/archive_pioneers/6502.shtml. Accessed 12 October 2011.

BBC (2001) 'Treasure Hunt - About Treasure Hunt', http://www.bbc.co.uk/cult/treasurehunt/about/index.shtml , accessed 5 Arpril 2012.

BBC (2012), 'John Peel's record collection to go online at The Space,' 23 February, http://www.bbc.co.uk/news/uk-england-suffolk17139449 , accessed 6 April.

Bambury, Adam (2011), 'Digging through the records at Perivale', Ariel, 5 April, http://www.bbc.co.uk/ariel/12970742. Accessed 10 October 2011. 
Berger, Jake (2011), 'Digital public space: Turning a big idea into a big thing, BBC Internet Blog, 14 October, http://www.bbc.co.uk/blogs/bbcinternet/2011/10/digital_public _space_idea.html, 6 February, accessed 20 November 2011.

Brown, Mark (2005), 'The BBC Treasure Hunt', http://www.btinternet.com/ m.brown1/bbchunt.htm , accessed 5 April 2012.

Brylawski, Samuel (2002) 'Preservation of digitally recorded sound', in Building a National Strategy for Digital Preservation: Issues in Digital Media Archiving, Washington, D.C.: Council on Library and Information Services/Library of Congress.

Bunz, Mercedes (2009), 'BBC and British Library to take joint approach to building digital archive', Guardian, 11 December, http://www.guardian.co.uk/media/2009/dec/11/bbcbritish-library-digital-archives. Accessed 10 October 2011.

Campbell, Debbie (2009), 'Digital best practice - a library viewpoint', in 16th annual Music Council of Australia Assembly, Melbourne, 28th September, at: http://www.nla.gov.au/openpublish/index.php/nlasp/artic le/viewArticle/1523, accessed 6 April 2012. 
Carpenter, Humphrey (1996) The Envy of the World: Fifty years of the BBC Third Programme and Radio 3, London: Weidenfeld and Nicolson.

Chapman, Robert (1992), Selling the Sixties: The Pirates and Pop Music Radio, London: Routledge.

Davies, Máire Messenger (2009), 'Archiving Television: History from the bottom up - two case studies', in Media in Transition 6: stone and papyrus, storage and transmission, Massachusetts Institute of Technology, Boston, USA, 25 April

Digital Curation Centre (2004), 'Interview with Richard Wright, Information and Archives, BBC', http://www.dcc.ac.uk/community/interviews/richard-wright. Accessed 10 October 2011.

Estelles-Arolas, Enrique, and Gonzalez-Ladron-de-Guevera, Fernando (2012), 'Towards an integrated crowdsourcing definition', Journal of Information Science, in press, also available at: http://www.crowdsourcing-blog.org/wpcontent/uploads/2012/02/Towards-an-integratedcrowdsourcing-definition-Estellés-González.pdf , accessed 5 April 2012. 
Fargion, Janet Topp (2004), 'African Music in the world and traditional music section at the British Library Sound Archive', History In Africa, 31, pp. 447-454.

500 Box (2011), collectively-authored pages on the Peel wiki, created September 2008, http://peel.wikia.com/wiki/500_Box. Accessed 25 November 2011.

400 Box (2011), collectively-authored pages on the Peel wiki, created July 2008, http://peel.wikia.com/wiki/400_Box. Accessed 20 November 2011.

Garner, Ken (1993), In Session Tonight: The Complete Radio 1 Recordings, London: BBC Books.

Garner, Ken (2007), The Peel Sessions: A Story of Teenage Dreams and One Man's Love of New Music, London: BBC Books.

Hills, Matt (2009), 'From BBC radio personality to online audience personae: the relevance of fan studies to Terry Wogan and the TOGS', The Radio Journal: International Studies in Broadcast and Audio Media, 7:1, pp. 67-88.

Howe, Jeff (2006), 'The rise of crowdsourcing', Wired, 14.06, June, http://www.wired.com/wired/archive/14.06/crowds.html , accessed 13 December 2012. 
Citation: Garner, Ken. 2012. 'Ripping the Pith from the Peel: Institutional and Internet Cultures of archiving pop

music radio', Radio Journal: International Studies in Broadcast and Audio Media, Vol 10 (2), pp. 89-112

Howe, Jeff (2009), Crowdsourcing: How the Power of the Crowd is Driving the Future of Business, London: Random House Business.

John Peel Centre (2012), 'Contents of John Peel's Record Collection to be made Public,' 23 February, http://johnpeelcentreforcreativearts.co.uk/index.php?option=c om_content\&view=article\&id=26:contents-of-john-peelsrecord-collection-to-be-madepublic\&catid=9:news\&Itemid=13 , accessed 6 April 2012 .

John Peel Wiki (2012), show calendar for 1979, for example, http://peel.wikia.com/wiki/1979, accessed 5 December 2012. Jones, Mark (1985), 'Interview: Mark Jones, Head of BBC Sound Archives,' in Archival Sound Recordings: Oral History of Recorded Sound, London: British Library, http://sounds.bl.uk/View.aspx?item=021M-C0090X0081XX0300V0.xml. Accessed 1 July 2010.

Kavanagh, Jacqueline (1999), ‘The BBC's Written Archives as a Source for Media History', Media History, 5:1, pp. 81-86.

Kavanagh, Jacqueline (2004), 'The BBC Written Archives', Records Management Journal, 14:2, pp.78-84.

Keating, Roly (2011), 'Permanent collections - the next stage in opening up the best of the BBC', About the BBC Blog, 
http://www.bbc.co.uk/blogs/aboutthebbc/2011/02/somethinghappened-today-that.shtml, 6 February, accessed 30 October 2011

King, Allan (2001), 'Preservation of the BBC Radio 1 Archive', in Audio Engineering Society, 20th International Conference: Archiving, Restoration, and New Methods of Recording, Budapest: Hungary, 5-7 October, Audio Engineering Society: New York.

Kiss, Jemima (2010a), 'Tech Weekly: In the BBC Archive', Guardian, podcast, 18 August, http://www.guardian.co.uk/technology/blog/audio/2010/aug/18 /bbc-archive-roly-keating-windmill-road. Accessed 13 December 2012.

Kiss, Jemima (2011), 'Tech Weekly: Creating a Digital Public Space', Guardian, podcast, 28 August, http://www.guardian.co.uk/technology/blog/audio/2011/sep/28/ tech-weekly-digital-public-space-audio. Accessed 13 December 2012.

Long, Paul (2006), 'The primary code: The meanings of John Peel, radio and popular music,' The Radio Journal: International Studies in Broadcast and Audio Media, 4:1-3, pp. 25-48. 
Nasaw, Daniel and Danzico, Matt (2011), 'Ravers and TimeTravellers re-record History', 8 November, $B B C$ News Magazine Chicago, http://www.bbc.co.uk/news/magazine15625457. Accessed 13 December 2012.

O'Carroll, Tristan (2008), 'BBC Worldwide to launch ad-backed online music service', MediaWeek, 27 August, http://www.mediaweek.co.uk/news/841648/, Accessed 30 November 2011.

Perry, Chris, and Howard, Simon (2010) 'Swiped or wiped? Kaleidoscope's part in the recovery of lost television programmes', Critical Studies in Television, 5:2, November, pp. 48-59.

Report of the Advisory Committee on Archives (1979), London:

British Broadcasting Corporation, April

Rooks, Simon (2009), 'The BBC Sound Archive', BBC Archive, http://www.bbc.co.uk/archive/sound_archive.shtml. Accessed 25 June 2010.

Rooks, Simon (2010), 'What happened to the BBC Sound Archive?', Journal of the Society of Archivists, 31:2, October, pp. 177185. 
Rothenbuhler, Eric W. (2006), 'John Peel in America', The Radio Journal: International Studies in Broadcast and Audio Media, 4:1-3, pp. 7-23.

Scannell, Paddy (2010), 'Television and History: Questioning the Archive', Communications Review, 13:1, pp. 37-51.

Skinner, Peter (2010), 'A new home for the BBC Archive,' on About the BBC Blog, 20 August, http://www.bbc.co.uk/blogs/aboutthebbc/2010/08/a-warmbalmy-afternoon-in.shtml. Accessed 12 October 2011.

SL Tapes (2011), collectively-authored pages on the Peel wiki, created September 2010, http://peel.wikia.com/wiki/SL_Tapes. Accessed 26 November 2011.

Spurgin, Kristina M. (2011) “"Three Backups is a Minimum”: A First Look at Norms and Practices in the Digital Photo Collections of Serious Photographers.' in Lee, Cal (ed.) I, Digital: Personal Collections in the Digital Era. Chicago: Society of American Archivists, pp. 151-201. Also available at: http://www.infomuse.net/papers/idigital/i-digitalchapter.pdf. Accessed 13 December 2012.

Stewart, Madeau (1986) 'Interview: Marie Slocombe: Sound Archives Librarian 1937-1972', 25 November, BBC Archive, 
http://www.bbc.co.uk/archive/archive_pioneers/6501.shtml. Accessed 12 October 2011.

Stewart, Madeau, and Fees, Craig (1996), 'Obituary: Marie Slocombe 1912-1995, Folk Music Journal, 7: 2, pp. 270-273.

Street, Sean (2007), 'Saving the sounds of history', 30 August, http://news.bbc.co.uk/1/hi/magazine/6968321.stm. Accessed 12 October 2011.

Svømmekjær, Heidi, and Larsen, Bente (2011), 'LARM Audio research archive - accessibility, visibility, research' at Radio Archive Summit, British Library, London, 15 December.

Thomas, Lyn (2009), 'The Archers: an everyday story of old and new media,' The Radio Journal: International Studies in Broadcast and Audio Media, 7:1, pp. 49-66.

Thompson, Bill (2011), 'Partnerships and the Digital Public Space', BBC Internet Blog, 10 October, http://www.bbc.co.uk/blogs/bbcinternet/2011/10/digital_public _space_partnersh.html. Accessed 13 December 2012.

Weaver, Julia (2009), 'Preserving the Sound Archive,' BBC Archive, http://www.bbc.co.uk/archive/preserving_sound.shtml. Accessed 25 June 2010. 
Winham, Richard P. (2008), 'The Power of Paradoxical Persona: An Analysis of John Peel's Radio Talk and Career at the BBC', Ph.D. Thesis, Knoxville, TN: University of Tennessee.

Wright, Richard (2001), 'Broadcast Archives: Preserving the Future', in Archives \& Museum Informatics, International Cultural Heritage Informatics Meeting ICHIM 01, Milan:

Italy, 3-7 September, Archives \& Museum Informatics: Toronto.

Wright, Richard (2004), 'Digital Preservation of Audio, Video and Film', Journal of Information and Knowledge Management Systems, 34: 2, pp. 71-76. 


\section{CONTRIBUTOR DETAILS}

Ken Garner teaches journalism in the Social Science, Media and Journalism department of Glasgow Caledonian University in Scotland. His main research interests are in radio, journalism, broadcast and film music. His published work includes most recently 'On Radio and Popular Music', in The Media in Scotland (Edinburgh, Edinburgh University Press, 2008), and The Peel Sessions (London: BBC Books, 2007). Forthcoming work includes chapters on radio policy and devolution in Scotland, and a reevaluation of Quentin Tarantino's film scoring practices in his postmillennial films. Ken previously worked as an arts, business and financial reporter, and from 1997-2002 was radio critic of the Sunday Express. He is founding editor of The Radio Journal. 
Citation: Garner, Ken. 2012. 'Ripping the Pith from the Peel: Institutional and Internet Cultures of archiving pop

music radio', Radio Journal: International Studies in Broadcast and Audio Media, Vol 10 (2), pp. 89-112

\title{
Endnotes
}

\begin{abstract}
i Some of the material in this article was presented in a paper of the same title at 'On, Archives! Celebrating 50 Years of the Wisconsin Center for Film and Theater Research - a conference on media, theater and history' 6-9 July 2010, Madison WI., USA.

ii See, for example: so_it_goes_2512, 2010, 'The Other Half', 8 August http://launch.groups.yahoo.com/group/peel/message/12341; stuartb, 2011, 'Composite 1st March 1992 now available', 13 September, http://launch.groups.yahoo.com/group/peel/message/15176 ; dr_mango2004, 2011, '1 September 1987 (remaster)', 22 July, http://launch.groups.yahoo.com/group/peel/message/14790 . iii Svømmekjær, Heidi, and Larsen, Bente (2011), 'LARM Audio research archive - accessibility, visibility, research', presentation at Radio Archive Summit, British Library, London, 15 December; and personal e-mail from Larsen (2012), 12 April. See also:
\end{abstract} http://www.larm-archive.org/about-larm/, accessed 5 April 2012. iv Rippers contributing to the online Peel projects use a variety of such applications for PC or Mac, such as Sound Forge, Total Recorder, BIAS Peak, Fission or (more expensively) ProTools, but the most common choice by far is the free digital audio editor Audacity, which unusually is available for Windows, Mac OS, and Linux, as well as other computer operating systems.

$\mathrm{v}$ In the event, copyright problems prevented the project from digitising and providing its own files of the album tracks; instead providing album cover art, Peel's index cards and other comments for the first 100 LPs under each letter of the alphabet, with monthly featured-album video commentaries. Audio was only available via links to spotify and other streaming services for a very small sample of the albums or sessions already commercially available in digital form. The project can be viewed here: http://thespace.org/items/p00019he?\&_suid=1354546688472012680 417858064175

vi Figures based on a search of the then publicly-accessible online 'Beta' version of the BBC INfax programme archive catalogue, conducted by the author in 2007. Neither this catalogue nor its replacement are currently publicly accessible.

vii The recordings were digitised in the European Broadcast Uniondeveloped Broadcast Wave Format (BWF), more commonly-known as BWAV, a version of the uncompressed WAV audio file format that allows for increased metadata about the item for cataloguing purposes to be embedded. For cost per copy reasons, the BWAV files 
were burned onto DVD-R discs for permanent storage, with compressed versions put on a server to allow producers to browse and select tracks online, after which a CD-R would be made and delivered internally for next day use in shows (see King, 2001; Wright, 2001, 2004; Digital Curation Centre, 2004). viii This close relationship between the BBC and the British Library on audio archival matters was underscored when director of archive content Roly Keating left the BBC to become the British Library's new chief executive in September 2012:

http://www.guardian.co.uk/media/2012/may/11/bbc-archive-directorroly-keating-leave

ix The first page sought basic data about the respondent, the second their listening habits (when/dates, age when listened, how long a listener, how regular a listener, and so on), the third recording practices (kinds of recordings made or acquired, how many recordings, continuous or interrupted, retention, sharing, preserving, downloading, digitising), followed by a page of ten likert-scale style 'strongly-agree' to 'strongly-disagree' responses invited to a series of opinion statements on the ethics of online archiving.

x The Survey was distributed as an online link via: the facebook pages of the author, John Peel (public figure), and the band The Wedding Present (one of Peel's favourites); the Yahoo groups John Peel, Fall-net (followers of Peel's favourite band), Ivor Cutler, Kevin Coyne, and What's Rattlin' (progressive rock); to more than $100 \mathrm{e}$ mail contacts for musicians, bands, and record labels known to the author who Peel had supported; Twitter, including several retweets; and the UK-media academic association MeCCSA e-mail discussion list on jiscmail. 